\title{
Estudo observacional das relações de poder no filme O Óleo de Lorenzo
}

\author{
Observational study of the power relationships in the movie Lorenzo's Oil
}

Fátima Regina Ney Matos ${ }^{1}$

Afonso Carneiro Lima ${ }^{2}$

Cláudia Maria Giesbrecht ${ }^{3}$

\section{Resumo}

A proposta deste artigo é analisar as relações de poder presentes no filme $O$ óleo de Lorenzo, que se baseia numa história real, mais ainda em construção. O trabalho toma como base argumentativa o estudo de Bourdieu (1993) sobre o campo científico, enfatizando a luta pelo monopólio da competência científica. A escolha do tema deveu-se ao recente reconhecimento, pela comunidade científica, da eficácia do medicamento conhecido como "óleo de Lorenzo", desenvolvido a partir de pesquisas feitas por Augusto e Michaela Odone, pais de Lorenzo e protagonistas da história. Aqui, foi realizado um estudo observacional, tipo de observação de "segunda mão", indireta e não participante. Na revisão bibliográfica tentou-se contextualizar, de maneira sucinta, o método científico e a origem das abordagens quantitativa e qualitativa, identificando, com base no filme, as relações de poder que permeiam o campo científico. É possível concluir que o discurso de autoridade científica é questionável e que a ruptura do monopólio da competência científica pode contribuir para ampliar o conhecimento, sem que necessariamente sejam alteradas as relações de poder.

Palavras-chave: estudo observacional; relações de poder; método científico.

\begin{abstract}
The purpose of this paper is to present a careful examination of the relations of power shown in the movie "Lorenzo's Oil", using as a basis for argument the work of Pierre Bourdieu (1993) concerning the scientific field, with emphasis on the struggle for the monopoly of scientific competence. The movie analyzed herein is based on a true and ongoing story. The motivation for the choice of this theme strems from the recent acknowledgement, by the scientific community, of the efficacy of the medicine known as “Lorenzo's Oil”, developed from research by August and Michaela Odone, Lorenzo's parents and protagonists of the story. The observational study was conducted as a kind of indirect observation with no participation by the researcher. As the paper unfolds, it attempts to place briefly in context the scientific method and the
\end{abstract}

Artigo submetido em dezembro de 2009 e aceito para publicação em março de 2010.

1 Doutora em Administração pela Universidade Federal de Pernambuco (PROPAD/UFPE); Professora adjunta do Programa de PósGraduação em Administração da Universidade de Fortaleza (UNIFOR). Endereço: Avenida Washington Soares, 1321, Bairro Edson Queiroz, CEP 60811.905, Fortaleza, Ceará. E-mail: fneymatos@globo.com

2 Doutorando e Mestre em Administração pela Faculdade de Economia e Administração da Universidade de São Paulo (USP). Endereço: Rua Válson Lopes, 101, Sala S3, CEP 055360-020, São Paulo, SP. E-mail: afonsolima@usp.br

3 Mestre em Administração pela Universidade Estadual do Ceará (UECE). Endereço: Alameda do Pomar, s/n, Condomínio Aconchego da Serra, Município de Itabirito, CEP 35450-000, Grande BH, Minas Gerais. E-mail: claudinhagis@gmail.com 
origin of both quantitative and qualitative approaches, identifying, based on the movie, the power relations that are inherent in the scientific field. It is possible to conclude that the speech of scientific authority can be questioned and that the rupture of the monopoly of the scientific ability may help to increase the amount of knowledge without necessarily modifying the relations of power.

Keywords: observational study; power relations; scientific method.

\section{Introdução}

Recebei a instrução e não o dinheiro. Preferi a ciência ao fino ouro, pois a sabedoria vale mais que as pérolas e joia alguma a pode igualar.

(Provérbios 8, 10-11)

Em sua presença na Terra, o homem sempre procurou tornar compreensíveis as coisas ao seu redor. Na Bíblia, um livro escrito há aproximadamente 6 mil anos, já se pode constatar a importância dada à ciência e ao saber.

Benedict (1982, p.235) considera a "história da raça humana uma sequência maravilhosa de progresso", progresso este intimamente relacionado ao conhecimento científico. É impossível precisar o período em que a ciência se tornou um conjunto complexo e sistemático de conhecimentos, mas, pode-se concluir que, a partir daí, o homem tornou-se um animal singular.

A ciência é uma invenção grega e veio substituir a mitologia como o acervo de conhecimento que o homem procurava para explicar a sua existência e o seu papel no mundo.

O advento da civilização grega que produziu tal explosão de atividade intelectual é um dos acontecimentos mais espetaculares da história. Jamais ocorreu algo semelhante, nem antes nem depois. No curto espaço de dois séculos os gregos produziram na arte, na literatura, na ciência e na filosofia uma assombrosa torrente de obras-primas que estabeleceram os padrões gerais da civilização ocidental. (RUSSELL, 2001, p.13 - grifo nosso)

Berço da civilização ocidental, a Grécia antiga nos legou "uma base objetiva para o conhecimento humano" (SOLIS, 1990, p.161): da lógica aristotélica - que predominou no ambiente científico por quase 2 mil anos a um dos primeiros tratados etnográficos conhecidos, a descrição feita por Heródoto sobre "os costumes, as vestimentas, as armas, os barcos, os tabus alimentares e as cerimônias religiosas dos persas e povos circunvizinhos" (GOLDENBERG, 2004, p.16).

Tão antigos quanto os métodos quantitativos, os métodos qualitativos foram gradativamente relegados a segundo plano no dito saber científico, embora concorde-se com Nunan (1994) que, em termos práticos, fazer uma separação rígida entre o quantitativo e o qualitativo seja simplista e ingênuo, já que ambos podem contribuir no desenvolvimento de um processo de investigação.

O objetivo deste estudo foi, através de uma abordagem qualitativa e da utilização de métodos visuais, analisar as relações de poder presentes no filme $O$ óleo de Lorenzo. Procurou-se usar como base argumentativa o trabalho de Bourdieu (1993) sobre o campo científico, com ênfase na luta pelo monopólio da competência científica. 
O filme analisado se baseia em uma história real, não retirada do passado, mas ainda em construção. O que motivou a escolha do tema foi o recente reconhecimento, pela comunidade científica, da eficácia do medicamento conhecido com "óleo de Lorenzo", desenvolvido a partir de pesquisas feitas por Augusto e Michaela Odone, pais de Lorenzo e protagonistas da história.

\section{Procedimentos metodológicos}

Cada vez mais, alguns recursos estéticos como filmes, romances, música e fotografias vem sendo utilizados no processo de ensino-aprendizagem, pois podem facilitar a construção de um link entre construtos teóricos e realidade prática. A observação é o método apropriado, de acordo com Cooper e Schindler (2003), para a análise de recursos estéticos, pois, além de possibilitar a coleta de dados visuais, envolve também a audição, o olfato e o tato.

Há uma diferença significativa entre o ato de observar rotineiramente a realidade e a interação com o mundo e o de examinar com "olhos clínicos"; isto é, observar apurada e sistematicamente para coletar dados (MERRIAN, 1998). A observação com "olhos clínicos" é "a base de toda investigação no campo da ciência social, podendo ser utilizada em trabalho científico de qualquer nível, desde os mais simples estágios até os mais avançados" (RICHARDSON, 1999, p.259).

Para que a observação se caracterize como investigação científica, deve obedecer a alguns critérios: ser conduzida especificamente para responder a uma questão de pesquisa, ser sistematicamente planejada, executada e registrada, usar controles apropriados e fornecer informações válidas e confiáveis sobre o objeto de estudo (COOPER e SCHINDLER, 2003; SELLTIZ et al, 1987).

Patton (2002) classifica o papel do observador, propondo um continuum entre participação total e participação como expectador. Na participação total, a observação é participante; na participação como expectador, o pesquisador desempenha apenas o papel de observador. Mesmo na participação como expectador, é possível ao pesquisador descrever locus, atividades e significados do que está sendo observado.

O uso de fotografias, filmes ou vídeos como objeto de análise constitui uma "observação de segunda mão" (FLICK, 2004, p.147), sendo considerado participação como expectador, o tipo de observação realizada neste estudo.

Como o observador não estava fisicamente presente, pode-se considerar também que foi realizada uma observação indireta:

\footnotetext{
A observação indireta é menos flexível do que a observação direta, mas também é muito menos tendenciosa e pode ser muito mais acurada. Outra vantagem da observação indireta é que o registro permanente pode ser reavaliado para incluir vários aspectos diferentes do fato. (COOPER e SCHINDLER, 2003, p.307)
}

Tomando como base o contínuo participante/observador proposto por Bogdan e Biklen (1994), foi priorizada a posição de "observador completo"; ou seja, "o investigador não participa em nenhuma das actividades do local onde decorre o estudo. Olha para a cena, no sentido literal [...]" (BOGDAN e BIKLEN, 1994, p.125).

Como o objetivo deste trabalho foi, através de uma abordagem qualitativa e da utilização de métodos visuais, analisar as relações de poder presentes no filme $O$ óleo de Lorenzo, pode-se considerar que foi feito um estudo observacional, com o observador como expectador (PATTON, 2002) ou observador completo (BOGDAN e BIKLEN, 1994), pois o tipo de observação foi de segunda mão (FLICK, 2004) e indireta, o que 
possibilitou ao pesquisador observar diversas vezes o lócus (filme), bem como o desenrolar das relações de poder.

Breves reflexões teóricas sobre a ciência...

A ciência é a estética da inteligência.

(Gaston Bachelard)

Na passagem do mito para a razão, da cosmologia aristotélica para a física moderna, o homem, em determinado ponto, passou a considerar científicas apenas as respostas obtidas através de métodos experimentais. De acordo com Solis (1990, p.162), a ciência moderna nasceu com Galileu e fundamentou-se nos princípios do método por ele proposto: observação dos fenômenos tais como eles ocorrem, experimentação e regularidade matemática. A partir daí, "o homem perdeu o seu lugar no Universo, perdeu a certeza dos céus depois da morte, [...] perdeu a segurança de seu mundo ordenado, hierarquizado, onde cada coisa ocupava o seu lugar próprio, segundo a sua natureza" (SIMON, 1990, p.128).

A língua falada pela ciência foi desvendada por Galileu e, desde então, os métodos experimentais adquiriram o status de mais científicos que os outros, tendo em vista sua ênfase em técnicas quantitativas.

A filosofia encontra-se escrita neste grande livro que continuamente se abre perante nossos olhos (isto é, o universo), que não se pode compreender antes de entender a língua e conhecer os caracteres com os quais está escrito. Ele está escrito em língua matemática, os caracteres são triângulos, circunferências e outras figuras geométricas, sem cujos meios é impossível entender humanamente as palavras; sem eles nós vagamos perdidos dentro de um obscuro labirinto. (GALILEU, 1978, p.119)

Se a ciência é uma invenção dos gregos, a ciência moderna, como hoje a conhecemos, eclodiu no período renascentista. De acordo com Morin (2000, p.),

A ciência moderna só pôde emergir na efervescência cultural da Renascença, na efervescência econômica, política e social do Ocidente europeu dos séculos XVI e XVII. Desde então, ela associou-se progressivamente à técnica, tornando-se tecnociência, e progressivamente se introduziu no coração das universidades, das sociedades, das empresas, dos Estados, transformando-os e se deixando transformar, por sua vez, pelo que ela transformava.

Nessa saga, ao atingir o século XIX, a ciência, de acordo com Comte (1978, p.65), "deixou essencialmente fora do movimento científico propriamente dito teorias morais e sociais, largadas então a um isolamento irracional, sob a estéril dominação do espírito teológico-metafísico."

Mesmo propondo o emprego do mesmo método para qualquer campo científico - "a única unidade indispensável é a unidade do método" - Comte colocava as ciências sociais em último lugar em sua divisão:

A filosofia positiva se encontra, pois, naturalmente dividida em cinco ciências fundamentais, cuja sucessão é determinada pela subordinação necessária e invariável, fundada, independentemente de toda opinião hipotética, na simples comparação 
aprofundada dos fenômenos correspondentes: a astronomia, a física, a química, a fisiologia e, enfim, a física social. (COMTE, 1978, p.33)

Possivelmente para justificar tão incômoda colocação da "física social", Durkheim $(2002$, p.11) colocou que "quase não estamos habituados a tratar cientificamente os fatos sociais". Propôs, então, regras para o método sociológico:

\begin{abstract}
Se há uma ciência das sociedades, é de se esperar que ela não consista simplesmente numa paráfrase dos preconceitos tradicionais, mas nos apresente as coisas de um modo diferente do que aparentam ao vulgo, pois o objeto de qualquer ciência é descobrir, e qualquer descobrimento desconcerta mais ou menos as opiniões estabelecidas. Desta forma, a menos que, em sociologia, se conceda ao senso comum uma autoridade que já há muito não tem nas outras ciências - não vemos de onde lhe poderia vir - o cientista deve tomar a decisão de não se intimidar pelos resultados a que levam as suas investigações, se foram metodicamente conduzidas. (DURKHEIM, 2002, p.11)
\end{abstract}

Em síntese, para Durkheim (2002, p.16), "os fatos sociais devem ser tratados como coisas", sendo desejável, inclusive, a utilização da estatística descritiva, como ocorreu em seu estudo sobre o suicídio. Esse estudo deu início, nas ciências humanas e sociais, ao uso excessivo do método positivista por parte dos pesquisadores dessas áreas, legitimando, no decorrer dos anos subsequentes, a falta de credibilidade e de confiança na pesquisa qualitativa.

De acordo com Alves-Mazzotti (2001, p.112), os pilares do positivismo, com sua ênfase na quantificação, foram duramente atingidos somente no século $\mathrm{XX}$, pelos questionamentos, principalmente, de Feyerabend (1977) e Kuhn (2005).

Sem "caos", não há conhecimento. Sem frequente renúncia à razão, não há progresso. Ideias que hoje constituem a base da ciência só existem porque houve coisas como o preconceito, a vaidade, a paixão; porque essas coisas se opõem à razão; e porque foi permitido que tivessem trânsito. Temos, portanto, de concluir que, mesmo no campo da ciência, não se deve e não se pode permitir que a razão seja exclusiva, devendo ela, frequentes vezes, ser posta de parte ou eliminada em prol de outras entidades. Não há uma só regra que seja válida em todas as circunstâncias, nem uma só instância a que se possa apelar em todas as situações. (FEYERABEND, 1977, p.279)

Tanto ou mais radical ainda, foi a proposta de Kuhn no ensaio A estrutura das revoluções científicas, escrito após "um envolvimento afortunado com um curso experimental da universidade, que apresentava a ciência física para os não-cientistas" (KUHN, 2005, p.9). As diferenças entre as comunidades formadas por diferentes tipos de cientistas (ciências naturais e ciências sociais) foram então identificadas e analisadas. Kuhn (2005, p.12-13) ficou "especialmente impressionado com o número e a extensão dos desacordos expressos existentes entre os cientistas sociais no que diz respeito à natureza dos métodos e problemas científicos legítimos".

Em um capítulo intitulado "o legado de Thomas Kuhn: o texto certo na hora certa", Geertz (2001, p.143) faz uma bela defesa de "Tom" e do seu ensaio, questionando e explicando porque a Estrutura teve tão grande impacto na comunidade científica.

Uma vez que o livro, originalmente concebido como um verbete independente da International encycolpedia of unified science, de Neurath, Carnap e Morris, de inspiração positivista, era muito esquemático, abrangente, confiante e intransigente, por si só ele 
estabeleceu os termos do debate. Tornou-se a imagem mesma do estudo da ciência como iniciativa mundana; tornou-se, para cunharmos uma expressão, seu paradigma dominante, pronto para ser imitado, ampliado, desdenhado ou derrubado. (GEERTZ, 2001, p.145)

O paradigma dominante quando a família Odone necessitou de um medicamento para seu único filho era de que, para aquele mal, não existia remédio e o prognóstico dado pela comunidade científica era a morte da criança em um curto espaço de tempo.

\title{
... e sobre o poder
}

Muito mais do que tornar-se conhecido, o poder manifesta-se sem uma identificação clara, sem dizer a que veio. Manifesta-se e "passa a existir entre os homens quando eles agem juntos [...]" (ARENDT, 2000, p.212).

Uma das principais artimanhas do poder é imiscuir-se entre os homens sem ser percebido, de modo disfarçado e carregado de subterfúgios. Muito mais do que mostrar-se, o poder utiliza disfarces. De acordo com Foucault (1985, p.83), "uma tática do poder é mascarar uma parte importante de si mesmo [...] estando seu sucesso na proporção daquilo que consegue ocultar."

É possível que se deva a essa característica de mascaramento a dificuldade para "escrever a história do poder. [...] A história da teoria política e da sociologia é em parte uma história de interminável desacordo sobre como o poder e a autoridade devem ser conceptualizados." (LUKES, 1980, p.823). Dificuldade, principalmente, porque o poder "não é uma entidade imutável, mensurável e confiável como a força." (ARENDT, 2000, p.212) e porque, na maioria das vezes, o poder torna-se invisível, "absolutamente 'discreto', pois funciona permanentemente e em grande parte em silêncio" (FOUCAULT, 1987, p.148).

O estudo das relações de poder sempre desafiou o homem. Já quatro séculos antes de Cristo, Aristóteles explicou a assimetria das relações de poder:

\begin{abstract}
Mandar e obedecer são condições não somente inevitáveis, mas também convenientes. Alguns seres, com efeito, desde a hora de seu nascimento são marcados para ser mandados ou para mandar, e há muitas espécies de mandantes e mandados (a autoridade é melhor quando exercida sobre súditos melhores; por exemplo, mandar num ser humano é melhor que mandar num animal selvagem; a obra é melhor quando executada por auxiliares melhores, e onde um homem manda e outro obedece pode-se dizer que houve mais obra), pois em todas as coisas compostas, onde uma pluralidade de partes, seja contínua ou descontínua, é combinada para constituir um todo único, sempre se verá alguém que manda e alguém que obedece, e esta peculiaridade dos seres vivos se acha presente neles como uma decorrência em seu todo, pois mesmo onde não há vida existe um princípio dominante, como no caso da harmonia musical. (ARISTÓTELES, 1988, p.19)
\end{abstract}

As relações de poder permeiam toda a história humana e sempre foram relacionadas a algum tipo de superioridade, seja a força física, os meios econômicos ou o conhecimento, entre tantos outros.

No século XVII, Bacon, cunhou a máxima "saber é poder". No aforismo III do Novum Organun, afirma que "a ciência e o poder do homem coincidem" (BACON, 1979, p.13). A partir daí, a ciência apropriou-se do conhecimento. Apenas o conhecimento considerado científico passou a ser legítimo, validado e aceito sem questionamentos. 
De acordo com Pagès et al (1987), o poder pode ser analisado sob quatro linhas de argumentação: marxista, psicanalítica, política e ideológica. A perspectiva ideológica procura analisar um fenômeno de apropriação do significado e dos valores; portanto, será priorizada neste estudo.

O poder é sempre relacional; ou seja, é preciso que existam pelo menos duas pessoas para que o mesmo se manifeste, é preciso que exista uma estrutura de ação coletiva. Pode-se afirmar que toda estrutura de ação coletiva, por ser uma construção humana, envolve um sistema de poder. Só quando "os atores têm um mínimo de autonomia é que se pode falar de relações de poder entre eles. E essa autonomia mede-se pela sua capacidade não teórica, mas real, de não fazer o que se espera deles, ou de fazer de forma diferente" (FRIEDBERG, 1993, p.255).

De acordo com Weber (2000, p.33), poder e dominação têm significados diferentes. Poder significaria "toda probabilidade de impor a própria vontade numa relação social, mesmo contra resistências, seja qual for o fundamento dessa probabilidade" e dominação ("autoridade"), "a probabilidade de encontrar obediência a uma ordem de determinado conteúdo, entre determinadas pessoas indicáveis".

Uma situação de dominação ocorre, segundo Thompson (1995, p.199), quando as relações de poder estabelecidas são sistematicamente assimétricas.

Relações de poder são sistematicamente assimétricas quando indivíduos ou grupos de indivíduos particulares possuem um poder de maneira estável, de tal modo que exclua - ou se torne inacessível, em grau significativo - a outros indivíduos ou grupos de indivíduos, não importando a base sobre a qual essa exclusão é levada a efeito. (THOMPSON, 1995, p.199-200)

A situação de assimetria nas relações de poder é clara no filme analisado. De um lado, a comunidade científica estabelecida, detentora da verdade científica e possuidora de um poder de maneira estável, de outro, os pais de Lorenzo, não participantes da referida comunidade.

A história contada no filme $O$ óleo de Lorenzo é real. Baseia-se no recorte de um determinado período da vida da família Odone, entre os anos de 1984 e 1995.

Lorenzo é filho de Augusto Odone, um economista que trabalha para o Banco Mundial, e Michaela Odone, uma mãe com dedicação exclusiva. Garoto saudável e inteligente, consegue aprender três línguas e adapta-se sem choques culturais à vida em uma comunidade nas Ilhas Comores.

Três meses após voltar para Washington, Lorenzo, então com seis anos, começa a apresentar distúrbios de comportamento, submetendo-se a uma série de exames. É diagnosticada uma doença rara, degenerativa, incurável e extremamente agressiva, que leva à morte em, no máximo, dois anos: a adrenoleucodistrofia (ALD). 
O diagnóstico foi dado por um especialista, o Dr. Judalon, o guardião do conhecimento científico, o profissional que possui uma autoridade instituída em seu campo do saber. Começa aqui a definir-se o que Bourdieu (1983, p.122) chama campo científico, que "é o lugar, o espaço de jogo de uma luta concorrencial", e o que Kuhn (2005, p.29) chama ciência normal, que "significa a pesquisa firmemente baseada em uma ou mais realizações científicas passadas. [...] reconhecidas durante algum tempo por alguma comunidade científica específica como proporcionando os fundamentos para sua prática posterior".

Para se compreender a ação do Dr. Judalon é preciso que se entenda o significado de campo e habitus, pois os dois são interdependentes. Para Bourdieu (2004), campo é um espaço de relações entre grupos, com distintos posicionamentos sociais, espaço de disputa e jogo de poder, e habitus é um processo gerador de ações impulsionadas e adaptadas a um determinado campo.

[...] Para que um campo funcione, é preciso que haja objetos de disputas e pessoas prontas a disputar o jogo, dotadas de habitus que impliquem conhecimento e o reconhecimento das leis imanentes do jogo, dos objetos de disputa. (BOURDIEU, 1983, p.89)

Segundo Bourdieu (1983), os diferentes campos formam-se a partir das relações existentes entre seus agentes internos - sejam de conflito ou aliança -, que se combatem pela posse de determinadas formas de capitais simbólicos, pois, assim, em consequência do capital alcançado, esses agentes tornam-se hegemônicos dentro do campo ao qual pertencem. Dessa forma, cada campo social implica uma forma predominante de capital. Essa concepção de campo e relação de poder, exposta por Bourdieu (2004), deixa transparente a reação do Dr. Judalon ao ser questionado pelos pais de Lorenzo sobre a possível forma de tratamento para a doença.

[...] precisamente aquilo que a noção de campo tinha em vista explicar: a realidade, as lutas que têm lugar no campo intelectual têm o poder simbólico como coisa em jogo, quer dizer, o que nelas está em jogo é o poder sobre o uso particular de uma categoria particular de sinais e, desse modo, sobre a visão e o sentido do mundo natural e social. (BOURDIEU, 2004, p.72)

Assim, o Dr. Judalon mostra que tem o monopólio da "competência científica", ou seja, "tem a capacidade de falar e de agir legitimamente" (id., 2004, p. 72), tem o respaldo da comunidade científica, tem o poder da palavra. A mãe, Susan Sarandon em uma interpretação primorosa, pergunta sobre as chances do garoto e se há uma possibilidade, mesmo remota, de cura. O cientista responde que não, com certeza absoluta, não existe nenhuma chance.

A especificidade do discurso de autoridade (curso, sermão etc.) reside no fato de que não basta que ele seja compreendido (em alguns casos, ele pode inclusive não ser compreendido sem perder seu poder), é preciso que ele seja reconhecido enquanto tal para que possa exercer seu efeito próprio. (BOURDIEU, 1988, p.91)

Os pais de Lorenzo começam uma busca desesperada pelos melhores especialistas em ALD. Recorrem, então, ao Dr. Gus Nikolais, que justifica o escasso conhecimento sobre a ALD pelo pouco tempo em que a doença foi identificada e pela falta de financiamento para as pesquisas. O Dr. Nikolais informa que morrem por ano, nos EUA, mais crianças engasgadas com batata frita do que com ALD, ou seja, não existem pacientes em número suficiente para que a indústria farmacêutica obtenha um retorno com seus gastos em pesquisa sobre o referido tema.

A luta pela obtenção de créditos e de instrumentos de pesquisa que hoje opõe os especialistas não se reduz jamais a uma simples luta pelo poder propriamente "político". Aqueles que estão à frente das grandes burocracias científicas só poderão impor sua vitória 
como uma vitória da ciência se forem capazes de impor uma definição de ciência que suponha que a boa maneira de fazer ciência implica a utilização de serviços de uma grande burocracia científica, provida de créditos, de equipamentos poderosos, de uma mão de obra abundante. [...] Assim, a tendência dos pesquisadores a se concentrar nos problemas considerados os mais importantes se explica pelo fato de que uma contribuição ou descoberta concernente a essas questões traz um lucro simbólico mais importante. (BOURDIEU, 1983, p.124)

Os Odone concordam em submeter Lorenzo a tratamentos experimentais invasivos e radicais, sem quaisquer resultados a não ser uma piora do estado geral do menino. Lorenzo é inscrito em um programa nutricional do Dr. Nikolais, que retira da dieta diária todos os alimentos que contêm cadeias longas de ácidos graxos. A hipótese é que a retirada da gordura saturada da dieta previne o seu acúmulo no cérebro. Os pais começam a observar que as taxas de Lorenzo não se reduzem, ao contrário, aumentam.

A partir daí, retiram a dieta e decidem pesquisar tudo sobre a função dos ácidos graxos no organismo, especialmente, sua relação com a perda da mielina, substância fundamental na intercomunicação neuronal.

Conseguem identificar um tipo de óleo puríssimo, encontrado, por coincidência, em uma pequena indústria química e resultante de uma experiência sem aplicação prática. Ainda não testado no organismo humano, o óleo começou a ser usado na dieta de Lorenzo e, pela primeira vez, o índice de ácidos graxos estacionou.

Dentro de uma interpretação mais profunda da obra de Bourdieu $(1983,1988,2004)$ para as ações dos Odone na busca frenética pela cura de Lorenzo, e consequentemente para sua descoberta paliativa, é importante lembrar o papel da estratégia na disputa dentro do campo cientifico. No contexto do filme, essa estratégia pode ser observada na série de ações ordenadas e estruturadas, desenvolvida em função de um conhecimento que proporciona a conquista de uma posição dominante dentro do campo.

Sobre as relações de poder, é importante salientar o papel da Fundação ALD, composta por 500 famílias que têm ou tiveram um membro vítima da doença. Em uma das reuniões, ao contestar os efeitos da dieta do Dr. Nikolais, os Odone são informados pelos líderes da fundação de que "não são cientistas, não interpretam testes, apenas financiam as pesquisas". Isto é, "os dominados são também dominados em seu cérebro" (BOURDIEU, 1990, p.57), pois mesmo diante de dados quantitativos (a estabilidade dos índices de ácidos graxos de cadeia longa no sangue de Lorenzo), preferem manter o saber canônico da ciência, uma vez que o mesmo está instituído e legitimado pela sociedade. Dessa perspectiva, a pesquisa "caseira" dos Odone constitui uma anomalia; ou seja, "o reconhecimento de que, de alguma maneira, a natureza violou as expectativas paradigmáticas que governam a ciência normal" (KUHN, 2005, p.78).

De acordo com Bourdieu (1983, p.122),

o que está em jogo especificamente nessa luta é o monopólio da autoridade científica definida, de maneira inseparável, como capacidade técnica e poder social; ou, se quisermos, o monopólio da competência científica, compreendida enquanto capacidade de falar e de agir legitimamente (isto é, de maneira autorizada e com autoridade), que é socialmente outorgada a um agente determinado.

É importante salientar que não se observa contradição alguma entre os tipos de saber indutivo e o autodidatismo de Augusto Odone. Augusto observa, formula, testa e refuta hipóteses através da experimentação. O que Augusto não tem é o saber legitimado, não pertence à comunidade científica, é um homem comum; ou seja, não tem "um nome próprio, um nome conhecido e reconhecido, marca que distingue 
imediatamente seu portador, arrancando-o como forma visível do fundo indiferenciado, despercebido, obscuro, no qual se perde o homem comum" (BOURDIEU, 1983, p.132).

Um último aspecto da observação refere-se às enfermeiras que colaboram no acompanhamento de Lorenzo. Incomodadas com o sofrimento do garoto e, sem esperança de que o quadro clínico possa ser revertido, comportam-se mais como profissionais da saúde, estabelecendo uma relação sujeito-objeto e mantendo uma distância segura do envolvimento emocional. Sentindo-se incomodada com o tratamento desumanizado das enfermeiras, que apenas cumprem suas tarefas, Michaela decide trazer um amigo de Lorenzo, o jovem Omuri, das Ilhas Comores.

O filme encerra-se com alguns garotos portadores de ALD tomando o "óleo de Lorenzo" e mantendo seus índices de ácidos graxos de cadeias longas estáveis. Lorenzo, com 17 anos, apresenta danos cerebrais irreversíveis, mas já consegue comunicar-se de forma rudimentar com as pessoas que o cercam.

\section{Conclusões}

A história de Lorenzo nos alerta para a arrogância que muitas vezes permeia o saber científico, tornando-o profundamente desvinculado dos valores humanos fundamentais, como o amor e o respeito ao próximo, que quase sempre permeiam o senso comum, mas devem ser erradicados do conhecimento científico.

Demo (2000, p.23) nos ensina que o senso comum deve ser respeitado, que

não é algo desprezível, muito ao contrário, é sobretudo com ele que organizamos nossa vida diária [...]. Em termos genéricos, o senso comum é a bagagem cultural e evolucionária que trazemos conosco, por meio da qual sabemos constituir família, educar os filhos, alimentarnos, cuidar da saúde, sem necessariamente sermos pedagogos ou médicos; nem está assegurado que, sendo pedagogo ou médico, saibamos melhor nos educar e curar; essa bagagem, em condições normais, não é colocada em questão e, por isso, faz parte da aceitação comum.

Ao fazer parte do acervo do senso comum, o conhecimento intuitivo é desprezado pela ciência. Entretanto, de acordo com Weber (1993, p.26), "no campo das ciências, a intuição do diletante pode ter significado tão grande quanto a do especialista e, por vezes, maior. Devemos, aliás, muitas das hipóteses mais frutíferas e dos conhecimentos de maior alcance a diletantes".

Augusto e Michaela Odone são diletantes, são pais e procuram negar "que o conhecimento precede os valores [...]" (BERGER e LUCKMAN, 2004, p.129). Mais importante que o conhecimento, são valores como o amor e a humildade, considerados por Bourdieu (2005) como bens simbólicos. Priorizando esses valores, talvez, se possa desenvolver uma atitude mais crítica quanto ao conhecimento científico e mais flexível em relação ao conhecimento intuitivo e aos saberes não científicos. Talvez, aprendamos que títulos acadêmicos não nos tornam necessariamente melhores que nossos semelhantes.

Os Odone não aceitaram o monopólio da autoridade científica, compreendida como capacidade de falar e de agir legitimamente, socialmente outorgada a um agente determinado, a comunidade da ciência médica. Promoveram uma ruptura no equilíbrio das relações existentes entre ciência e senso comum; desobedeceram às regras do jogo, no sentido de não aceitar como verdade absoluta um diagnóstico médico e o prognóstico sobre a doença de Lorenzo. 
Augusto Odone questiona o saber canônico da ciência em um caso específico, acreditando que "não há teoria final, prova cabal, prática intocável” (DEMO, 1995, p.11). Após exaustiva pesquisa bibliográfica sobre o assunto, ALD, e com base em alguns estudos ainda incipientes sobre determinados óleos, segue os passos clássicos do método científico, observando, formulando, testando e refutando algumas hipóteses. Ao fazer uma experimentação, acaba por encontrar um tipo de óleo puríssimo ainda não testado no organismo humano, que, inserido na dieta de Lorenzo fez estacionar, pela primeira vez, o índice de ácidos graxos.

A comunidade científica, após longos anos, reconheceu a eficácia do "óleo de Lorenzo", que teve sua comprovação científica em uma pesquisa longitudinal coordenada pelo neurologista Hugo Mozer, publicada na revista New Scientist. A comunidade científica, então, cooptou Augusto Odone como membro, outorgando-lhe o diploma honorário de medicina. Assim, é possível concluir que o discurso de autoridade científica pode ser questionado e que a ruptura do monopólio da competência científica pode contribuir para aumentar o acervo de conhecimento, sem necessariamente alterar as relações de poder.

\section{Referências}

ALVES-MAZZOTTI, Alda Judith; GEWANDSZNAJDER, Fernando. O método nas ciências naturais e sociais pesquisa quantitativa e qualitativa. São Paulo: Pioneira, 2001.

ARENDT, Hannah. A condição humana. 10.ed. Rio de Janeiro: Forense Universitária, 2000.

ARISTÓTELES. Política. Brasília, DF: Editora da Universidade de Brasília, 1988.

BACHELARD. G. A formação do espírito científico: contribuição para uma psicanálise do conhecimento. Rio de Janeiro: Contraponto, 1996.

BACON, Francis. Novum Organun. São Paulo: Abril Cultural, 1979. (Coleção Os Pensadores).

BENEDICT, Ruth. O desenvolvimento da cultura. In: SHAPIRO, Harry L. Homem, cultura e sociedade. São Paulo: Martins Fontes, 1982.

BERGER, Peter L.; LUCKMAN, Thomas. A construção social da realidade. Petrópolis: Editora Vozes, 2004.

BOGDAN, R.; BIKLEN, S. Investigação qualitativa em educação - uma introdução à teoria e aos métodos. Porto, Pt: Editora Porto Ltda., 1994.

BOURDIEU, Pierre. O campo científico. In: ORTIZ, Renato (Org.). Sociologia. São Paulo: Ática, 1983.

. A economia das trocas linguísticas: o que falar quer dizer. São Paulo: Edusp, 1988.

Coisas ditas. São Paulo: Brasiliense, 1990.

Razões práticas - sobre a teoria da ação. 6.ed. Campinas, SP: Papirus, 2004.

COMTE, Auguste. Curso de filosofia positiva. São Paulo: Abril Cultural, 1978.

COOPER, D. R.; SCHINDLER, P. S. Métodos de pesquisa em administração. 7.ed. Porto Alegre: Bookman, 2003.

DEMO, Pedro. Metodologia científica em ciências sociais. 3.ed. São Paulo: Atlas, 1995.

Metodologia do conhecimento científico. São Paulo: Atlas, 2000.

DURKHEIM. Émile. As regras do método sociológico. São Paulo: Martin Claret, 2002.

FEYERABEND, P. Contra o método. Rio de Janeiro: Francisco Alves, 1977. 
FLICK Uwe. Uma introdução à pesquisa qualitativa. Porto Alegre: Bookman, 2004.

FOUCAULT, Michel. História da sexualidade I: a vontade de saber. Rio de Janeiro: Edições Graal, 1985.

Vigiar e punir. Petrópolis: Vozes, 1987.

FRIEDBERG, Erhard. O poder e a regra - dinâmicas da acção organizada. Lisboa: Instituto Piaget, 1993.

GALILEI, Galileu. O ensaiador. São Paulo: Abril Cultural, 1978. (Coleção Os Pensadores).

GEERTZ, Clifort. Nova luz sobre a antropologia. Rio de Janeiro: Jorge Zahar Ed., 2001.

GOLDENBERG, Mirian. A arte de pesquisar - como fazer pesquisa qualitativa em ciências sociais. 8.ed. Rio de Janeiro: Record, 2004

KUHN, Thomas S. A estrutura das revoluções científicas. 9.ed. São Paulo: Perspectiva, 2005.

LIVRO dos provérbios. Bíblia sagrada. São Paulo: Editora Ave Maria, 1984.

LUKES, Steven. Poder e autoridade. In: BOTTOMORE, T.; NISBET, R. História da análise sociológica. Rio de Janeiro: Zahar Editores, 1980.

MERRIAN, S. B. Qualitative research and case study applications in education. San Francisco: Jossey-Bass Publishers, 1998.

MORIN, Edgar. Ciência com consciência. Rio de Janeiro: Bertrand Brasil, 2000.

NUNAN, David. Research methods in language learning. New York: Cambridge University Press, 1994.

PAGÈS, Max et al. O poder nas organizações. São Paulo: Atlas, 1987.

PATTON, Michael Q. Qualitative research and evaluation methods. London: Sage Publications, 2002.

RICHARDSON, Roberto J. e colaboradores. Pesquisa social - métodos e técnicas. 3.ed ver. e aum. São Paulo: Atlas, 1999.

RUSSELL, Bertrand. História do pensamento ocidental - a aventura das ideias: dos pré-socráticos a Wittgenstein. Rio de Janeiro: Ediouro, 2001

SELLTIZ, Claire et al.Métodos de pesquisa nas relações sociais. São Paulo: Edusp, 1987.

SIMON, Maria Célia. Galileu Galilei. In: HÜHNE, Leda Miranda (Org.). Metodologia científica - caderno de textos e técnicas. 4.ed. Rio de Janeiro: Agir, 1990.

SOLIS, Sidney Sérgio Fernandes. O método experimental-dedutivo e a revolução galileu-cartesiana. In: HÜHNE, Leda Miranda (Org.). Metodologia científica - caderno de textos e técnicas. 4.ed. Rio de Janeiro: Agir, 1990.

THOMPSON, John B. Ideologia e cultura moderna - teoria social crítica na era dos meios de comunicação de massa. 5.ed. Petrópolis: Editora Vozes, 1995.

WEBER, Max. Ciência e política: duas vocações. São Paulo: Cultrix, 1993.

Economia e sociedade: fundamentos da sociologia compreensiva. 3.ed. Brasília, DF: Editora Universidade de Brasília, 2000. 